Dhaka Univ. J. Biol. Sci. 28(1): 37-47, 2019 (January)

\title{
EFFECTS OF AFLATOXIN B1 CONTAMINATED FEED ON THAI KOI
}

\author{
Afroza Sultana Eti, Matiur Rahim ${ }^{1}$ and Mahmud Hasan* \\ Department of Fisheries, University of Dhaka, Dhaka-1000, Bangladesh
}

Key words: Aflatoxin B1, Contaminated Feed, Thai koi

\begin{abstract}
The effects of five levels of aflatoxin B1 (0, 25, 50, 100 and $200 \mathrm{ppb})$ and three $(15,30$ and 45 days) culture durations on the growth performances and residue concentration in Thai koi, Anabas testudineus was investigated in indoor plastic tanks. Significant differences were found in 100 and $200 \mathrm{ppb}$ treatment groups in average daily weight gain (ADG, g/d) and specific growth rate (SGR, \%/d) compared to those of control, 25 and $50 \mathrm{ppb}$ treatments group. Body muscle in $200 \mathrm{ppb}$ treatment group had significantly higher concentration of aflatoxin $\mathrm{B}_{1}$ (AFB) residue than in the 100 and $50 \mathrm{ppb}$ treatments. Control and $25 \mathrm{ppb}$ treatments group did not have any residue. Total protein and fat contents decreased compared to control, 25 and $50 \mathrm{ppb}$ treatments group. The results suggested that the level of contamination by 50,100 and $200 \mathrm{ppb}$ aflatoxin $\mathrm{B}_{1}$ in the feed of Thai koi fingerlings may concentrate in the body muscle at a level of above human health hazards. Any feeds with even $50 \mathrm{ppb}$ AFB1 should not be used as feed for raising food fishes.
\end{abstract}

\section{Introduction}

Air breathing climbing perch Anabus testudineus locally called koi is a commercially cultured high value fish in Bangladesh. This hardy fish is suitable for cultivation in ponds, reservoirs and rice fields. Production of Thai koi is very optimistic in fulfilling the upcoming demand of this fish for food security and human nutrition.

Aflatoxin are a group of mycotoxins primarily produced by certain strains of Aspergillus flavus and Aspergillus parasiticus, and rarely, by the related species Aspergillus nomius, and Aspergillus niger ${ }^{(1)}$. $\mathrm{AFB}_{1}, \mathrm{AFB}_{2}, \mathrm{AFG}_{1}$ and $\mathrm{AFG}_{2}$ are the direct contaminants of foods and feeds. A. flavus produces only $\mathrm{AFB}_{1}$ and $\mathrm{AFB}_{2}{ }^{(2)}$. Aflatoxin $\mathrm{B}_{1}$ is the most common in food and amongst the most potent genotoxic and carcinogenic aflatoxins.

Aflatoxin contamination in aqua feeds, a widespread problem in aquaculture due to use of waste materials. Many feed ingredients used in aquaculture such as soybean, rice bran, dried fish, shrimp and fish meal have been found to be frequently contaminated by aflatoxin ${ }^{(3)}$. The study of aflatoxin $\mathrm{B}_{1}$ on fish has received increasing attention in recent years with special focus on its strong carcinogenic, mutagenic and teratogenic effects ${ }^{(4-5)}$. While rainbow trout, Oncorhynchus mykiss are extremely sensitive to a low dose of $\mathrm{AFB}^{(6)}$,

*Author for correspondence: <mhasan@du.ac.bd>. ${ }^{1}$ Food Toxicology Research Section, Institute of Food Science and Technology (IFST), BCSIR, Dhaka-1205, Bangladesh. 
channel catfish, Ictalurus punctatus is responsive only at high doses ${ }^{(7)}$. However, the effects of aflatoxin $B_{1}$ on the survival, growth performances and residues in the tissues have not reported in Thai koi culture practices.

The objective of this study was to determine the effects of AFB1 on the growth performances of Thai koi.

\section{Materials and Methods}

Experimental fish, Thai koi $(1.5$ months old $)(4.21 \pm 0.18 \mathrm{~cm} ; 1.79 \pm 0.40 \mathrm{~g}$, mean \pm SEM) was collected from a nursery of Trishal Upazilla of Mymenshing. While experiment was undertaken in University of Dhaka, the analytical part was performed in Food Toxicology Research Section, IFST, BCSIR, Dhaka.

Before experimentation, the fish was conditioned in the laboratory over a period of three days. During conditioning, the fish was fasted to evacuate their previous gut contents. After fasting, the length and weight of the fish were measured.

Fifteen cylindrical, dark blue 750 liter plastic tanks were used as the experimental systems. The tanks were placed by following the Completely Randomized Design (CRD). The experimental variables were five doses of AFB and three culture durations. The indicator variables were survival rate, SGR, ADG and residue concentration of AFB in the muscle.

Each tank was filled in with 700 liter pond water for rearing fish. Dissolved oxygen concentration (DO) $(5-5.65)$ and $\mathrm{pH}(7.5$ - 8.5) of the tank water was measured by using a portable DO meter and $\mathrm{pH}$ meter, respectively. Each experimental unit was stocked with 30 fish. The study was conducted over a period of 45 days between June and July, 2011.

The experimental feed was fortified with toxicant aflatoxin supplied by Food Toxicology Research Section, IFST, BCSIR.

Commercial pellet diet (Pangas startar cramble) of Aftab Feed Products (Islam Group Ltd., Rupashi, Rupganj, Narayanganj) was used in the experiment. All feed contained equal amounts of all ingredients, except the level of $\mathrm{AFB}_{1}$ as follows: control contained 0 ppb AFB 1 , and treatment II, III, IV and V had 25, 50, 100 and 200 ppb AFB 1 , respectively. $\mathrm{AFB}_{1}$ was diluted with Acetonitryl and added to the feed by sprayer. This process was followed by 24 hrs of drying in 'Fume Hood' until the moisture content was lower than $10 \%$. The dry feeds were wrapped in two layers of black plastic bags and held in desiccators until used. The fish was fed twice a day, morning (between 8 and 9 a.m.) and afternoon (between 4 and 5 p.m.). Feeding frequency was maintained 5\% of their body weight (BW). The samples were collected 3 times at every 15 days interval from each experimental unit. 
Survival rate (\%) was measured on the basis of total fish harvested at the end of each fortnight until the end of the study.

Specific growth rate and average daily weight gain were measured following the methods described by Hopkins ${ }^{(8)}$.

Fish tissue was analyzed by HPLC (High Performance Liquid Chromatography, Model No. Agilent: 1100 Series) method( ${ }^{(9)}$.

At the beginning, fins, head, scales, skin and other parts of the body were removed from the treated fish and the muscles were scrapped off from the vertebra bones as clear as possible. Muscle was macerated in a blender to produce a homogenous mass.

The moisture content was determined by air oven method(10). Pre weighted samples were dried at $105^{\circ} \mathrm{C}$ for 10 hours and reported moisture content as loss of weight. Finally the percentage of moisture content was detected. Crude protein was measured by "Micro- Kjeldhal" method (Model Tecator Kjeltec System 1026 Manual, 1987). Protein conversion factor (6.25) was used in converting nitrogen to crude protein. Crude lipid was determined by using the Soxhlet system (Model Tecator Soxtec System HT 1043-001 Manual, 1983).

All data were transformed into square root before statistical analysis. One-way ANOVA was used to determine the differences between concentration and control with HSD post hoc for multiple comparisons. Statistical software SPSS version 16.0 was used with the level of significance at $p<0.05$.

\section{Results and Discussion}

Zero mortality was found during the entire period of experiment. Average daily weight gain dropped progressively with increasing the concentration of aflatoxin $B_{1}$ in the feed (Fig. 1). However, similar but significantly lower ADG was observed in 100 and $200 \mathrm{ppb}$ treatment groups. Control group had the highest ADG. SGR declined gradually with increased concentration of aflatoxin $B_{1}$ in the feed. Significantly higher SGR was detected in control group than that of other treatment groups.

Increasing trends of aflatoxin $\mathrm{B}_{1}$ residue was observed in the fish tissue of Thai koi. No aflatoxin $\mathrm{B}_{1}$ was detected in control and $25 \mathrm{ppb}$ treatment groups while significantly higher concentration was detected in 200 ppb treatment group (Fig. 1).

While no mortality has been found in this study, increased mortality has been reported in Nile tilapia when fed feed with an aflatoxin $B_{1}$ concentration of $100000 \mathrm{ppb}$ for 8 weeks although $10000 \mathrm{ppb}$ has not resulted in different level of mortality ${ }^{(11)}$. Much higher concentration of aflatoxin $\mathrm{B}_{1}(30000 \mathrm{ppb})$ in Nile tilapia for 25 days period has not resulted in any mortality ${ }^{(12)}$. However, AFB as low as 100 and $200 \mathrm{ppb}$ in the fish diet has been found to reduce growth in Thai koi. This study has clearly demonstrated that low doses of aflatoxin $B_{1}(25,50,100$ and $200 \mathrm{ppb})$ have no effect on the survival of Thai koi. 
This has also been indicated that concentration of aflatoxin $B_{1}$ residue in fish muscle is proportional to that in the diet.

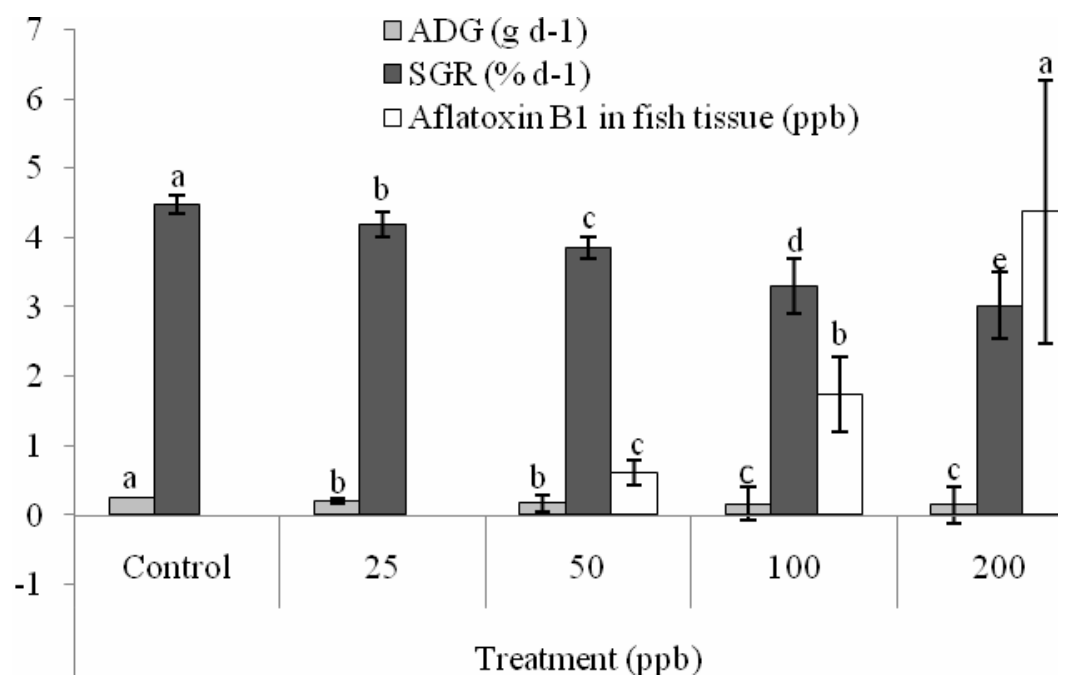

Fig. 1. Overall effects of aflatoxin $B_{1}$ on the average daily weight gain, specific growth rate and residue in fish tissue at different levels of aflatoxin $B_{1}$. Bars (mean \pm SEM) with same color, different letters are significantly different $(\mathrm{p}<0.05)$.

The mortality observed in this study in Thai koi after feeding diets containing 25, 50, 100 and 200 ppb AFB levels over 15, 30 and 45 days culture duration perhaps because of no toxicity or less toxicity at these levels. Akter et. al.(5) found no mortality in common carp when fed feed with an aflatoxin $\mathrm{B}_{1}$ concentration of $100 \mathrm{ppb}$ for 30 days period. On the other hand, Chavez-Sanchez et al.(13) did not find any mortality by feeding diets containing $30000 \mathrm{ppb}$ aflatoxin $\mathrm{B}_{1}$ in Nile tilapia for 25 days. No mortality as observed in the present study also reveals the less effect of low dose aflatoxin $B_{1}(25,50,100$ and 200 $\mathrm{ppb}$ ). Cent percent survivals over a period of 45 days at $200 \mathrm{ppb}$ of aflatoxin $\mathrm{B}_{1}$ also indicate the lesser toxicity that may fail to compromise the Thai koi ability to struggle for survival.

Significantly higher ADG was detected at 15 and 30 day culture duration than that 45-day (Fig. 2). Again, significantly higher SGR was found at 30-day culture duration than that of 15 and 45 day durations. No residue of aflatoxin $B_{1}$ was detected in fish tissue of Thai koi at 15 day culture duration while significantly higher aflatoxin $\mathrm{B}_{1}$ residue was observed at 45 day culture duration than did 30 day culture duration (Fig. 2).

In the control group, the highest SGR $4.89 \pm 0.17\left(\% \mathrm{~d}^{-1}\right)$ was found at 30 -day culture duration while the lowest $3.93 \pm 0.14$ (\%/d) was observed at 45-day culture duration (Fig. 3). However, similar ADG was detected in all culture durations. No residue of aflatoxin $B_{1}$ was found in fish tissue in any sampling duration. 
Significantly higher SGR in the $25 \mathrm{ppb}$ treatment group was found at 30-day culture duration than that of others. Similar but significantly higher ADG was detected in 15 and 30-day culture durations than in the 45-day culture duration while similar ADG was observed in 15 and 45-day culture durations (Fig. 4).

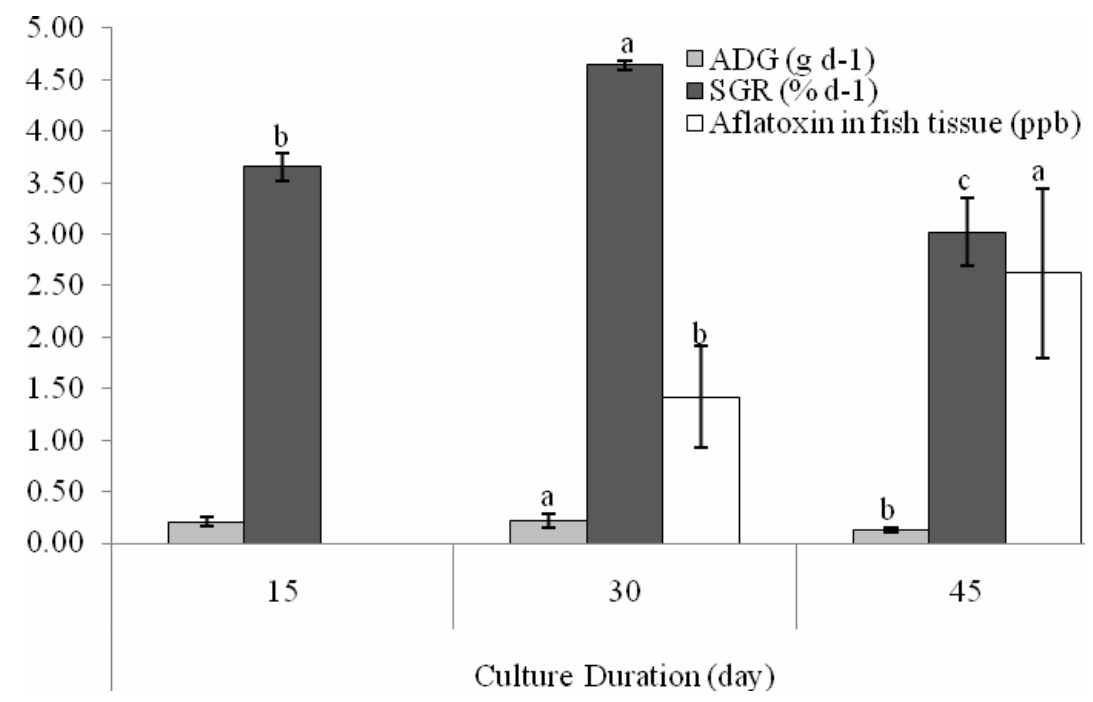

Fig. 2. Overall effects of aflatoxin $B_{1}$ on the average daily weight gain, specific growth rate and aflatoxin $B_{1}$ residue in fish tissue at different culture durations (day). Bars (mean $\pm S E M$ ) with same color, different letters denote significant differences $(\mathrm{p}<0.05)$.

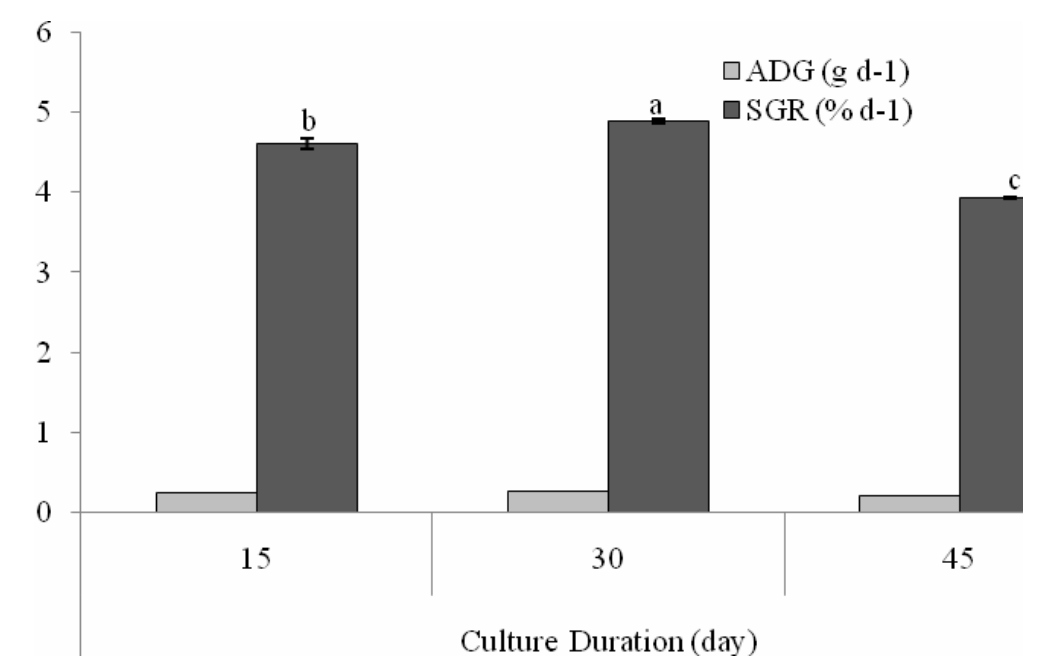

Fig. 3. Average daily weight gain, specific growth rate and residue in fish tissue of control group at different sampling durations (day). Bars (mean \pm SEM) with same color, different letters are significantly different $(\mathrm{p}<0.05)$. 


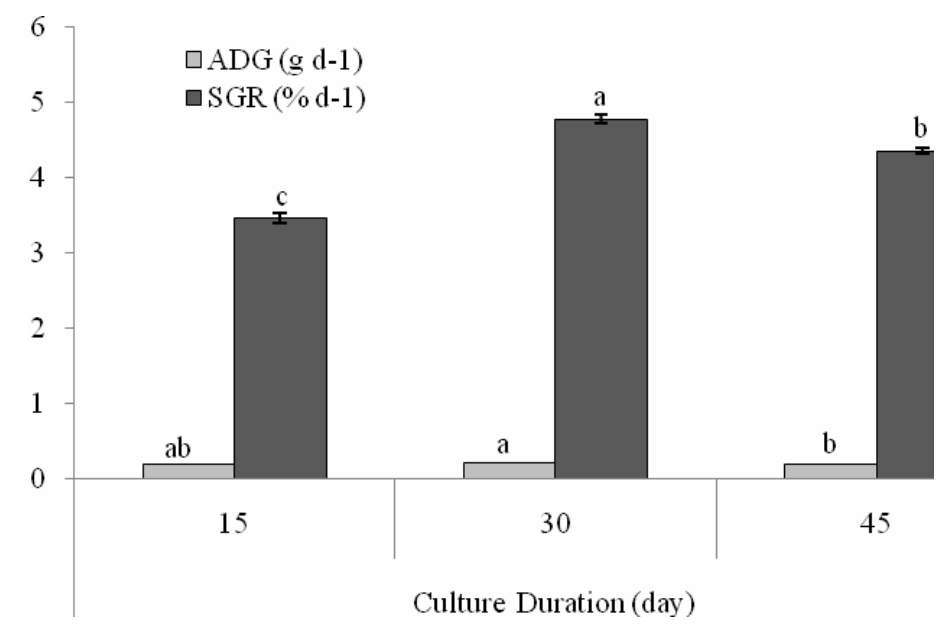

Fig. 4. The average daily weight gain, specific growth rate and residue in fish tissue of $25 \mathrm{ppb}$ treatment group in different culture durations (day). Bars (mean $\pm S E M)$ with same color, different letters indicate significant differences $(\mathrm{p}<0.05)$.

In $50 \mathrm{ppb}$ treatment group, the highest SGR $4.46 \pm 0.17\left(\% \mathrm{~d}^{-1}\right)$ was found in 30-day culture while similar SGR was detected at 15 and 45-day culture duration (Fig. 5). However, similar ADG was detected in all three culture durations. Besides, significantly higher aflatoxin $B_{1}$ residue was found at 45-day sampling than that of 30-day sampling while no residue was detected at 15-day.

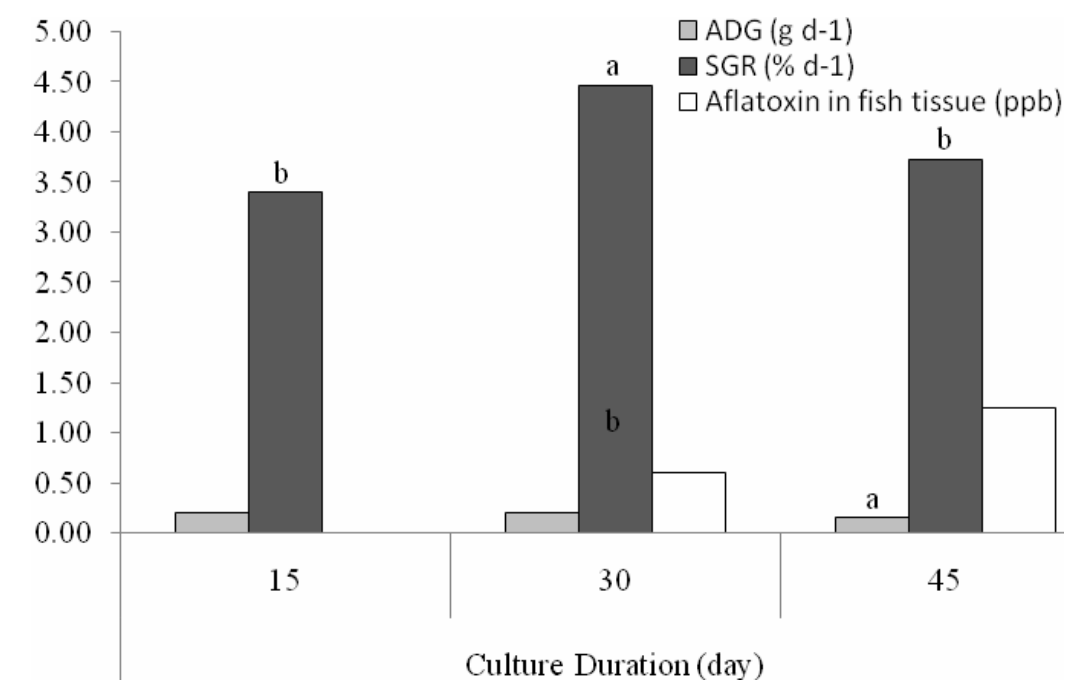

Fig. 5. The average daily weight gain, specific growth rate and residue in fish tissue of treatment III (50 ppb) at different culture durations (day). Bars (mean \pm SEM) with same color, different letters are significantly different $(\mathrm{p}<0.05)$. 
Similar but significantly higher ADG was detected at 15 and 30-day culture duration than that of 45-day (Fig. 6). Significantly higher SGR was found at 30-day culture duration than that of 15 and 45-day culture durations. No residue of aflatoxin $\mathrm{B}_{1}$ was detected in fish tissue of Thai koi at 15-day culture duration while significantly higher aflatoxin $B_{1}$ residue was observed at 45-day culture duration than that of 30-day (Fig. 6).

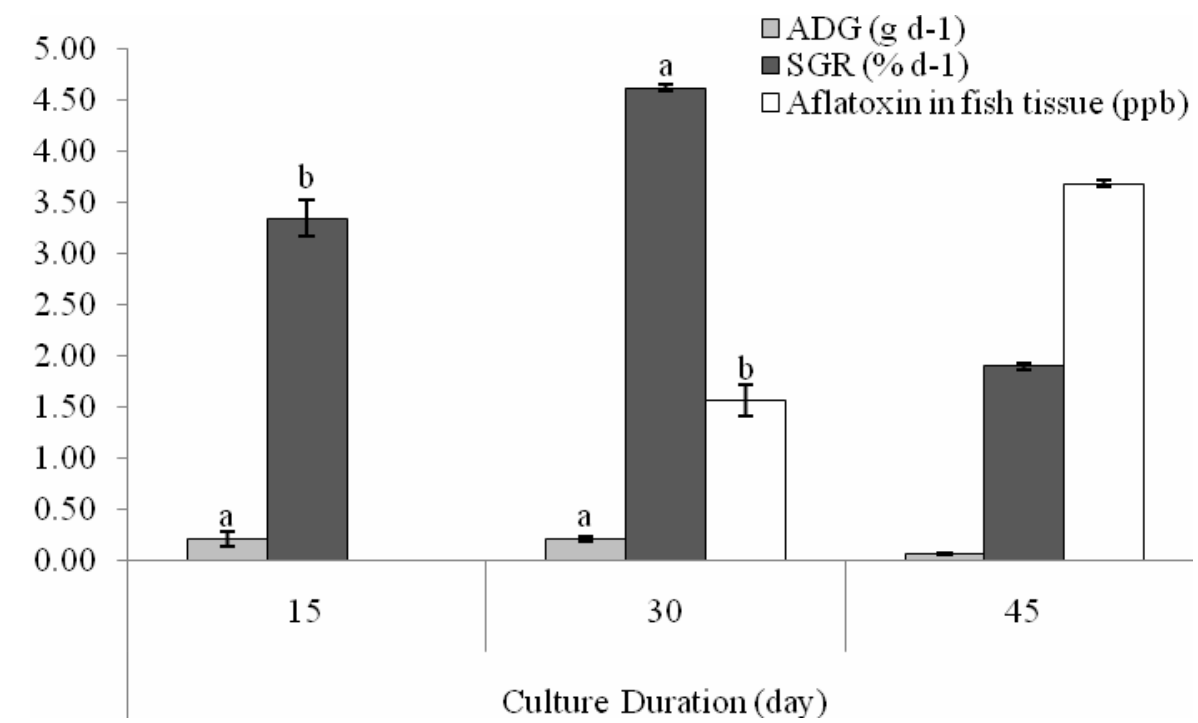

Fig. 6. Average daily weight gain, specific growth rate and residue in fish tissue of treatment IV $(100 \mathrm{ppb})$ at different sampling duration (day). Bars (mean $\pm \mathrm{SEM}$ ) with same color, different letters indicate significant difference $(\mathrm{p}<0.05)$.

Similar but significantly higher ADG was detected at 15 and 30-day culture duration than that of 45-day (Fig. 7). Significantly higher SGR was found at 30-day culture duration than that of 15 and 45-day culture durations. No residue of aflatoxin $B_{1}$ was detected in fish tissue of Thai koi at 15-day culture duration while significantly higher aflatoxin $B_{1}$ residue was observed at 45-day culture duration than that of 30-day culture duration (Fig. 7).

The observed lower ADG and SGR in fish tissue in different $\mathrm{AFB}_{1}$ concentration in the current study showed negative effects of aflatoxin $B_{1}$ in Thai koi performance for growth. These lower performances in these dimensions of Thai koi growth were perhaps because of the incapability or reduced protein utilization efficiencies. Aflatoxin $B_{1}$ could have affected the activities of enzymes in the digestion, absorption and assimilation of protein. The compromised ability in growth parameters of Thai koi showed high sensitivity of Thai koi to aflatoxin B1. Grey mullet has been found to be highly sensitive to AFB followed by common carp, red and Nile tilapia ${ }^{(14)}$. Reduced weight gain has been found in tilapia when fed feed containing 100000 ppb AFB but 250 ppb did not do the 
same. Tilapia did not differ in weight gain when fed diet containing $250 \mathrm{ppb}$ aflatoxin than that of the control group; however, diets containing higher levels (100000 ppb) of AFB had significantly reduced weight gain ${ }^{(12)}$. Chavez-Sanchez et al.(13) have found that Nile tilapia had reduced growth rate and feed intake when fed feed containing AFB 0-3000 ppb. Akter et al.(5) confirmed that average daily weight gain and specific growth rate in common carp when fed diets containing $100 \mathrm{ppb}$ AFB are significantly different from that of the control and $50 \mathrm{ppb}$ treatment groups. However, channel catfish, Ictalums punctatus fed feed with $2150 \mathrm{ppb}$ for a period of 10 weeks has no significant change in growth while only a 24 per cent reduction in growth rate has been found when fed feed with $10000 \mathrm{ppb}$ of aflatoxin $\mathrm{B}_{1}{ }^{(8)}$. Dietary aflatoxin $\mathrm{B}_{1}$ treatment has been found to decrease feed consumption, growth performance and feed and nutrient utilization. Additionally, catfish has been found to be more resistant than tilapia to aflatoxicosis ${ }^{(16)}$. However, catfish contained more residual aflatoxin $\mathrm{B}_{1}$ than tilapia which has led to a conclusion that aflatoxin metabolism is species specific. The adverse effects of aflatoxin on feed conversion and body weight gain have been found that could be because of anorexia, listlessness, inhibition of protein synthesis and lipogenesis ${ }^{(14)}$. Impaired liver functions and protein/lipid utilization mechanisms may also have affected the growth performance and general health ${ }^{(16)}$.

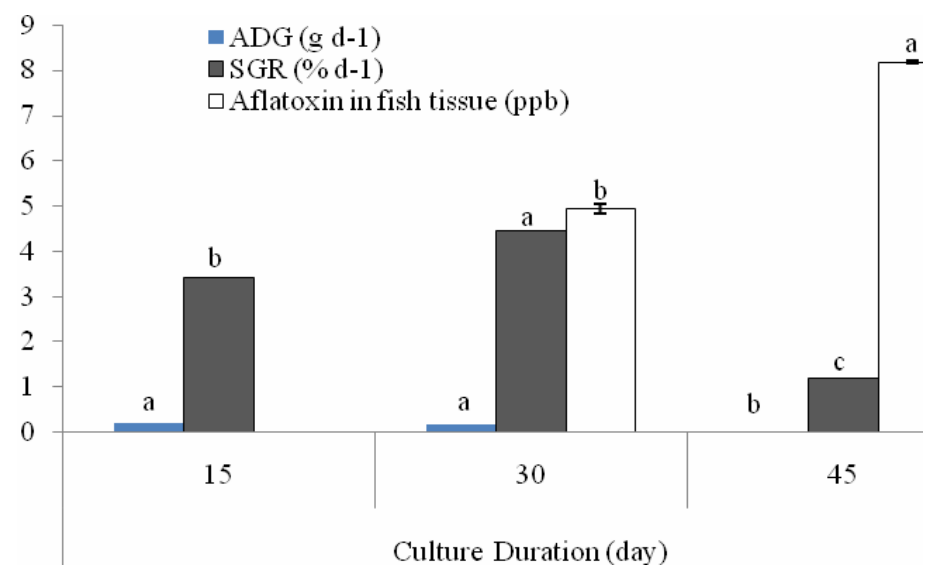

Fig. 7. Average daily weight gain, specific growth rate and residue in fish tissue of treatment V (200 $\mathrm{ppb}$ ) at different culture durations (day). Bars (mean \pm SEM) with same color, different letters are significantly different $(\mathrm{p}<0.05)$.

The observed highest concentration of aflatoxin $B_{1}$ residue in the muscle of Thai koi in $200 \mathrm{ppb}$ treatment groups indicates AFB deposition in muscle. The persistence of AFB depends on the potentiality of accumulation in fishes. Hussain et al.(16) has demonstrated in walleye Sander vitreus for 30 days period that 50 or $100 \mathrm{ppb}$ aflatoxin $\mathrm{B}_{1}$ has resulted in $20 \mathrm{ppb}$ residues of aflatoxins $\mathrm{B}_{1}, \mathrm{G}_{1}$ and $\mathrm{G}_{2}$ in muscles. Catfish has found to clear faster AFB residues ${ }^{(17)}$. 
Significantly higher moisture was found in 100 and $200 \mathrm{ppb}$ treatment group than that of other groups. Similar but significantly lower moisture was detected in control and $25 \mathrm{ppb}$ treatment group than that of other treatment groups (Fig. 8a).

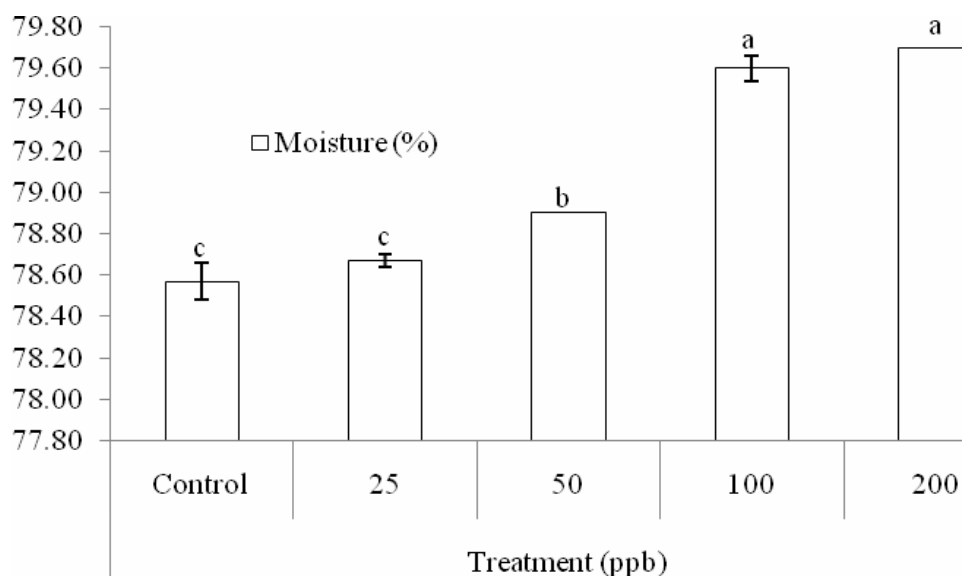

Fig. 8a: Effects of $\mathrm{AFB}_{1}$ on total moisture content of Thai koi at different treatment groups. Bars (mean \pm SEM) different letters denote significant difference $(\mathrm{p}<0.05)$.

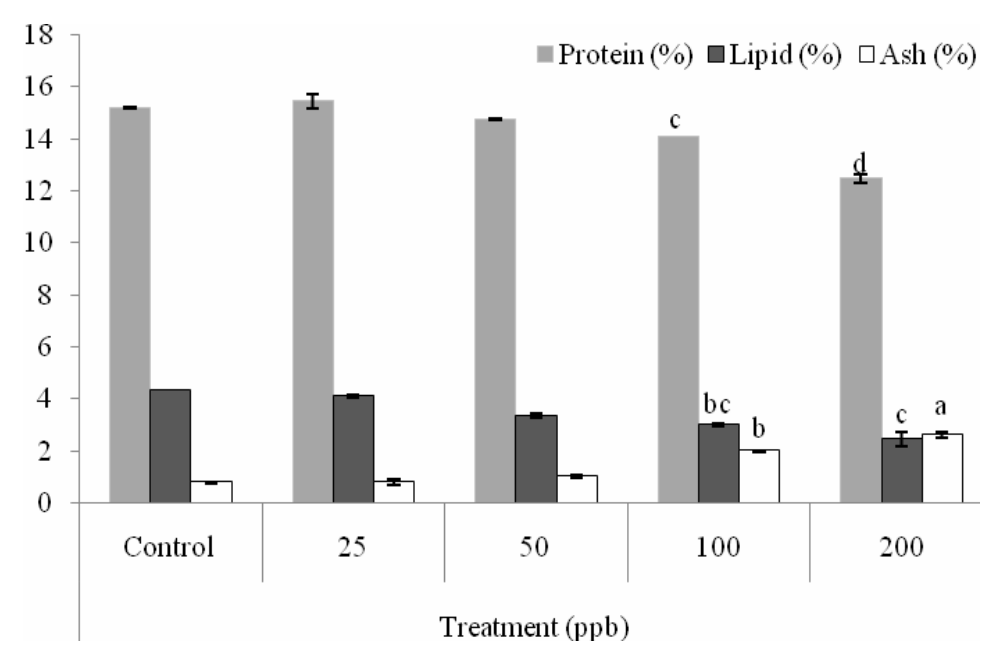

Fig. 8b. Effects of $\mathrm{AFB}_{1}$ on protein, lipid and ash content of Thai koi at different treatment groups. Bars (mean \pm SEM) with same color, different letters are significantly different $(\mathrm{p}<0.05)$.

Similar but significantly higher protein was detected in $25 \mathrm{ppb}$ concentration and control groups while similar protein was observed in control and $50 \mathrm{ppb}$ treatment groups. In contrast, the protein level of $100 \mathrm{ppb}$ and $200 \mathrm{ppb}$ treatment group are significantly different (Fig. 8b). 
Significantly higher lipid was found in control and $25 \mathrm{ppb}$ treatment groups than that of other treatments groups. Lower lipid content was detected in $200 \mathrm{ppb}$ concentration but similar to $100 \mathrm{ppb}$ concentration. On the other hand, lipid content in 50 $\mathrm{ppb}$ and $100 \mathrm{ppb}$ concentration groups were similar.

The observed lower protein and fat content in the current study showed negative effects of aflatoxin $B_{1}$ in Thai koi performance for nutritional point of view. The reduction of protein content may be explained by the increased metabolism of protein due to increased activation of metabolic enzyme by $\mathrm{AFB}_{1}$ treatment. The result is also supported by other reporters in which the investigators showed reduction of muscle total protein content of the treated fishes in a concentration dependant manner in A. testudineus (18-20) . They observed that percentage of crude protein decreased as the level of dietary AFB increased.

The highest level of ash content in Thai koi was found in $200 \mathrm{ppb}$ concentration of aflatoxin $\mathrm{B}_{1}$ than that of all other treatment groups. However, similar but lower ash content was detected in control and $25 \mathrm{ppb}$ concentration. Conversely, $50 \mathrm{ppb}$ and 100 ppb concentration groups were significantly different.

Lower ADG and SGR with increasing duration in the current study signify protein utilization efficiency decreased with increasing the duration of $\mathrm{AFB}_{1}$ exposure. Significantly higher SGR at 30 days duration was found perhaps because of asymmetrical growth and body defense against toxocity. Higher aflatoxin $\mathrm{B}_{1}$ residues in the muscle with increasing duration imply higher potential accumulation of AFB in Thai koi.

The results of this study have demonstrated that Thai koi fingerling is significantly affected by aflatoxin $B_{1}$. The metabolites of aflatoxin $B_{1}$ can easily accumulate in the edible part of the body which might be contaminated to human body through biological magnification via food chain. Growth of Thai koi may be severely affected if the feed is contaminated with aflatoxin $\mathrm{B}_{1}$ as high as $200 \mathrm{ppb}$.

\section{References}

1. Militâ, NM Mihâeecu and G Chifirue 2010. C. Aflatoxins- Health risk factors. Bacterial Viirusol arazito Epidemiol. 55: 19-24.

2. D’Mello JPF and AMC MacDonald 1997. Animal Feed Science Technology 69: 155-166.

3. Spring P 2005. Mycotoxins - a rising threat to aquaculture, Feedmix 13: 5.

4. Santacroce MP, MC Conversano, E Casalino, O Lai, C.Zizzadoro, G Centoducati and G Crescenzo 2008. Aflatoxinsin aquatic species: metabolism, toxicity and perspectives. Rev. FishBiol. Fisheries 18: 99130.

5. Akter A, M Rahim and M Hasan 2010. Effects of aflatoxin $B_{1}$ on the growth and bioacumulation in common carp fingerling in Bangladesh. Asia-Pacific Journal of Rural Development 20(2): 1-14. 
6. Hendricks JD 1994. Carcinogenecity of aflatoxins in non mammalian organisms. In Eaton DL, Groopmen JD (eds) The Toxicology of Aflatoxins : Human Health, Veterinary, and Agricultural Significance. Academic Press, New York. pp. 103-136.

7. Jantrarotai W, RT Lovell and J M Grizzle. 1990. Acute toxicity of dietary aflatoxin B 1 to channel catfish. J. Aquat. Anim. Heaith 2: 237-247.

8. Hopkins KD 1992. Reporting fish growth: A review of the basics. J. World Aquaculture.

9. Jarvis BB, D Midiwo, D Tuhill and GA Bean 1981. Interaction between the antibiotic Trichotheccenes and the higher plant Baccharis megapotamic. Science 214: 460-462.

10. AOAC 1997. Association of Official Analytical Chemists International Official Methods of analysis. $16^{\text {th }}$ Edition, AOAC, Arlington.

11. Tuan NA, JM Grizzle, RT Lovell, BB Manning and GE Rottinghaus 2002. Growth and hepatic Leisor of Nile tilapa (Oreochromis niloticus) fed diets containing aflatoxin B1. Aquaculture 212: 311-319.

12. Chárez-Sánchezet MaC, CA Martinez Palacios, and I Osario Moreno 1994. Pathological effects of feeding young Oreochromis niloticus diets supplemented with different levels of Aflatoxin B1. pp. 49-60.

13. Omar E, Srour T, and A Nour 1996. Effects of aflatoxin contaminated feeds on some freshwater fishes. roc. Conf. Food borne contamination and Egyptian's Health, Mansoura, 26-27 Nov. pp. 71-84.

14. Abdelhamid AM, FF Khalil and MA Ragab 1997. Problem of mycotoxin in fish production. Peoc. $6^{\text {th }}$ Conf. of Anim, Poult., and Fish Nutrition. El-Menia Univ., Egypt. Nov. 1997 (Abs) pp. 349-350.

15. Ortatatli M and H Oguz 2001. Ameliorative effects of dietary clinoptilolite on pathological changes in broiler chickens during aflatoxicosis. Res. Vet. Science 71: 59-66.

16. . Hussain M, T Wilson and RC Summerfelt 1993. Effect of Aflatoxin-contaminated feed on morbidity and residues in walleye fish. Vet. And Human Toxical. 35(5): 396-398.

17. Plakas SM, PM Loveland, GS Baily, VS Blazer and G.L. Wilson 1991. Tissue disposition and exertion of 14 C-labeled aflatoxin B1 after oral administration in channel catfish. Food and Chem. Toxical. 29: 805-808.

18. Hossain SY, IAA Mekkawy, ZZ Mokter and M Mubarak 2000. Protective effects of Nigella sativa seed against aflatoxicosis in Oreochomis niloticus. Pycotoxins and Diatoxins and the Environment, Bydgoszez, 25-27 Sep., pp. 109-130.

19. Salem MFE 2002. Effects of dietary graded levels of aflatoxin B1 on growth performances and chromosomal behavior of Nile tilapa Oreochromis niloticus. Ph. D. Thesis, kafi El-Sheikh, Tanta Univ.

20. Abdelhamid AM, AI Mehrim and FF Khalil 2004. Detoxification of aflatoxin contaminated diet of tilapia fish using dietary supplementation with egg shell, Bentafin, clay or silica. J. Agric. Sci. Mansoura Univ. 29: 3163-3174. 